\title{
GOVERNMENTAL CONTROL OF THE FORMATION EFFICIENCY OF EDUCATIONAL CLUSTERS AT THE REGIONAL LEVEL
}

\author{
Nina Ivanovna Larionova, Tatiana Valerievna Yalyalieva, \\ Dmitry Leonidovich Napolskikh and Victor Evgenevich Shebashev
}

Department of Management and Law, Volga State University of Technology, 424000 Yoshkar-Ola, Russia

Received 2014-08-27; Revised 2014-09-30; Accepted 2014-10-03

\begin{abstract}
Studying the cluster institutionalization processes in the modern practices of the social development allows determining the formation trends of an efficient governmental control system at the subfederal level. The efficiency parameters suggested by the author for the cluster policy implementation for the governmental control purposes, such as density, integrity, complementarity and institutional sphere conductivity will allow controlling the development efficiency of the educational clusters in the modern reality. The research shows that the formation of the governmental control mechanisms and instruments is based on a general study of the institutional aspects of the cluster policy. It has been determined that the main driving force and the main actor of the modernization processes at the regional level is the scientific community. The educational clusters have their potential both for generating fundamental and applied knowledge and for managing innovation projects. Education is a mobile self-organizing system, with its intellectual resources acting as a strategic resource of modernization for the regions of Russia.
\end{abstract}

Keywords: Governmental Control, Economical Institutions, Economy Clustering, Efficiency of Institutions

\section{INTRODUCTION}

In the modern conditions, the competitiveness of the subfederal cluster territory is interpreted as a concentrated expression of the production, scientific and technical and organizational institutional advantages implemented in high technology goods and services (Porter, 2009). Analyzing the innovation clusters using the "triple spiral" model allowed revealing the dialectical correlation between the development stages of educational clusters and the life cycle of an innovation. The multi-subject composition of the parties of the contract relations within a cluster can be classified according to the subject composition of the "triple spiral" model, i.e., it appears possible to single out "the state" (state and self-government bodies), "business" and "universities" (Enright, 1996).

The cluster policy efficiency, in its wide meaning, should be interpreted as the aggregate efficiency of the work, actions and the system of measures. The aggregate social and economic effect produced through implementation of governmental programs, which is achieved by applying structural modifications to the economy, can be used as the efficiency indicator (Feldman, 1994).

When analyzing the efficiency for the control purposes, it is required to consider the main principles that the financing of the state expenses is based on (including those when allotting the funds intended implementation of the target programs). In this case, the 424000 Yoshkar-Ola, Russia 
methods used to assess the educational clusters can be applied to control the efficiency of the use of the state resources (Dritsaki and Adamopoulos, 2005).

Implementation of the cluster policy for territorial development is based not only on building an innovation business support infrastructure but also on the formation of a network interaction structure between innovation businesses and the governmental bodies. In this regard, studying the institutional development aspects of the governmental mechanisms used to control the cluster policy efficiency at the subfederal level becomes an important scientific task.

\section{DATA AND METHOD}

In the context of the network analysis of the innovation cluster institutional environment, it is expedient to use the instruments of the mathematical graph theory. Every node of an oriented graph has both inbound and outbound edges building the relation parameters for a particular node: The number of inbound edges and the number of the outbound ones. Basing on those parameters, we make a conclusion on the level of "the actor centrality" in the structure of the network correlations.

Considering the development criteria of the institutional environment of an educational cluster, we can single out such parameters as the density of the institutional environment and its innovation conductivity, which produce effect on the diffusion speed of the management and production innovations within the cluster. Let us make an assumption that any economical agent of the innovation cluster may be connected with other economical subjects through identifiable bilateral relations, both direct connections and indirect ones operating through intermediaries, with formal interactions prevailing with the former and non-formal interactions ensured by the institutional environment prevailing with the latter.

The cluster institutional environment density can be characterized as the ratio of the stable formal connections between the cluster organizations and businesses to their total number. The cluster institutional environment density can be represented with the formula below:

$$
p=\frac{\sum\left(s x_{1}, s x_{2} \ldots s x_{n}\right)}{n}
$$

Where:

$p=$ The cluster institutional environment density

$s x_{i}=$ The number of the stable formal connections between the $i^{\text {th }}$ cluster agent with the other ones

$n=$ The number of the cluster agents

Considering the cluster institutional environment density, it is required to single out the institutional environment integrity parameters related to the cluster. The cluster institutional environment integrity can be characterized as the ratio of the sum of the number of the indirect connections of each cluster agent with the other ones to their total number:

$$
q=\frac{\sum\left(u x_{1}, u x_{2} \ldots u x_{n}\right)}{n}
$$

Where:

$q=$ The cluster institutional environment integrity

$u x_{i}=$ The number of the cluster agents connected with indirect non-formal connections with the $i^{\text {th }}$ cluster agent

$n=$ The number of the cluster agents

The cluster institutional environment complementarity can be characterized as the average number of the primary communication channels between each cluster agent and the other ones:

$$
k=\frac{\sum\left(a x_{1}, a x_{2} \ldots a x_{n}\right)}{n}
$$

Where:

$k=$ The cluster institutional environment complementarity

$a x_{i}=$ The number of the primary communication channels between each cluster agent and the other ones

$n=$ The number of the cluster agents

The cluster institutional environment conductivity is considered as the average length of the bilateral interaction chains between the cluster organizations and businesses which are not directly interconnected but build communication channels for innovation diffusion, technology transfer, as well as for informational and sociocultural interactions between the cluster agents. The cluster institutional environment conductivity can be represented with the formula below. 


$$
\phi=\frac{\sum\left(L x_{1} x_{2}, L x_{1} x_{3} \ldots L x_{2} x_{1} \ldots L x_{m} x_{n}\right)}{\sum x_{i} x_{j}}
$$

Where:

$$
\begin{aligned}
\varphi= & \text { The cluster institutional environment } \\
& \text { conductivity } \\
x_{i} x_{j}= & \text { The communication channel between the } i^{\text {th }} \text { and } \\
& \text { the } j^{\text {th }} \text { cluster agents which are not directly } \\
& \text { interconnected }(i=1 \ldots m ; j=1 \ldots n) \\
L x_{i} x_{j}= & \text { The aggregate length of the bilateral interaction } \\
& \text { chains between the cluster agents building the } \\
& \text { communication channel }
\end{aligned}
$$

\section{ANALYSIS AND RESULTS}

Using the territorial method to identify and assess the development of educational clusters allows assessing the synergetic effect produced by the interaction between educational institutions and innovation businesses within a region. A local innovation educational sphere is created in the territory of the educational cluster, which is intended for providing educational services, outside the region as well.

It was found out in the course of the research that educational clusters do not only broaden and develop but, in time, they can also become narrower and disintegrate. This kind of dynamics and flexibility of educational clusters represents their distinctive feature and requires permanent governmental control if compared to other organizational forms of the education system. In time, efficient active clusters become objects of big governmental investments. The kernel of the cluster is normally represented by several "high status" educational institutions which preserve competition between one another. The concentration of the "rivals", their "consumers" and "providers" contributes to the growth of the efficient specialization of the scientific and educational activities. At the same time, the cluster stimulates the development of a lot of "non-status" educational institutions. The educational institutions uniting into a cluster on the basis of vertical and horizontal integration build a unified distribution sphere for new knowledge and technologies and the essential condition for the efficient transformation from inventions to innovations and then from innovations to competitive advantages is establishing a network of stable connections between all the cluster agents.

The local commercial marketing interests crossing those of the governmental marketing become the essential condition for the education clustering, with the modern reality taken into account. On the one hand, education still remains a socially important sphere, as the society needs wider reproduction of the intellectual potential. On the other hand, there is a labor market, while the market for educational services is being built and the educational institutions are acting as full-grown agents of the market relations.

With the education clustering processes taking place on the labor market controlled by the state, the following aspects are examined: Demand for the corresponding specialists, employer requirements for the specialists, market trends assessment and market segmentation. Considering the peculiarity of the "product" of the educational institutions, i.e., the specialists being the consumer of the educational services at the same time, it appears difficult to verify the quality of the knowledge they acquired at the moment the graduates are hired. Hence, it appears important to study and assess the institutional conditions and the requirements for the university graduates. As for the pricing policy of the education market, the cost of a specialist can be determined on the mutually beneficial terms, considering the capacities and requirements of each of the sectors of the educational cluster. One of the functions of the educational clusters is promotion of the graduates on the labor market, e.g. establishing collaboration channels between its agents (direct contracts with companies, field experience with further employment and cooperation with public and commercial placement agencies), which also contribute to building the required image of the graduates and the educational institution itself.

Using the education clustering concept when implementing the innovation model of the regional social and economic development implies the following: Considering the requirements of the labor market (both local and global), studying the groups of potential consumers of the educational services (direct relation principle) and improving the mechanisms of the market for educational services by using the marketing complex (feedback principle).

We believe the governmental control of the formation efficiency of educational clusters at the regional level should be started from determining the principles that the development parameters for the particular type of clusters have to follow. These parameters have to correspond to the requirements as follows:

- The parameters have to characterize the cost volume and the dynamics of the services provided by the education system 
- They should indicate the position of those services in the total volume of paid services

- Since the costs of the education sphere are mainly built at the expenses of the budget system, the parameters have to characterize those costs

- The parameters should reflect the structure of the educational institutions and the number of students with respect to public and commercial organizations

- The parameters have to characterize the industrial structure of the market, as well as the education forms and the implementation costs of the educational process

The efficiency parameters suggested above are intended to ensure the optimal ratio of the educational organizations making the educational cluster, based on the assessment of their competitive ability and innovativeness. When an educational institution joins the educational cluster, it improves the quality of the educational services provision thanks to elimination of the duplicating educational programs and discontinuation of similar services provision by different institutions.

Thus, using the system of the cluster institution environment development parameters ensures several basic tasks fulfilled in relation to the governmental control of the education system management efficiency: Strategic planning of the number and composition of educational organizations, their compliance with the regional demand for human resources and optimization of the costs required for maintaining the property of the educational institutions.

In the context of the governmental control of the educational cluster efficiency it appears reasonable to work out three scenarios (short-term, medium-term and long-term), under which the system determines the number and particular composition of the educational organizations making the cluster. The system is based on the methods of scenario modeling and allows performing scenario analysis depending on the variations of the forecasted demand for the human resources in the region.

The task of control and monitoring, as well as efficiency assessment and optimization of the institutional collaboration networks of educational organizations is common for the entire education system of the country.

\section{DISCUSSION}

From the position of the institutional theory, the functioning sphere of the institutions represents an environment that is commonly called institutional. Many representatives of the institutional school of economics, including the Noble Prize winner Ronald Coase, mainly concentrated their attention on studying the institutional aspects of the economical transactions, thus considering the institutional environment of any territory to be conditioned by the exogenous factors. The study of the institutional environment of a territory as an evolving endogenous factor was initiated by the representatives of the school of economics of Washington University in the 1970s (Coase, 1992).

Douglass North uses the institutional environment term to define the institutional limits which exist at the macro level and determine the possible conditions of contractual agreements between individuals (North, 1994). Oliver Williamson defines the institutional environment as an established system of the informal "rules of the game" which build the sociocultural context of economic activity (Williamson, 2000).

In the context of this research, the institutional environment is interpreted as the aggregate of the institutions and institutional connections which surround and fill the subfederal economic system and produce their effect on it. The cluster institutional environment creates favorable conditions for the formation of an interaction network between the cluster agents and governmental bodies (Liu and Chen, 2004). At the same time, while changing in the course of time, the institutional aspects of the governmental control mechanisms form the limits of the economic behavior of innovation companies, thus establishing the sociocultural norms taking effect on the behavior of the agents of economy (Kim et al., 2014). On the other hand, the development degree of the governmental control mechanisms applied to the cluster policy efficiency at the subfederal level is determined by the activities of various groups of interests within the cluster, while the effect they produce on the environment depends on the level of the institutional control of the interrelations inside those groups.

\section{CONCLUSION}

An indisputable advantage of the suggested system of the parameters for the purposes of governmental control of the educational cluster efficiency is its versatility, as it is adapted to any kind of education system and is valid in the conditions of establishing an uninterrupted education system.

The solution for the problem of educational process efficiency control depends on how timely and adequately 
the educational clusters will react to the changes of the external environment and to the needs of the society. The modern governmental control system of education efficiency is another step for Russia on its way to enter the European and the world educational space. The presented results of the research can be applied to the governmental control domain in the conditions of the developing economics of knowledge. The cluster institutional environment efficiency parameters suggested in this article were used by the governmental bodies of the Mari El Republic, Russia, when working on the programs for innovation development of the region and that of the educational clusters in particular. It is planned to implement the results of future scientific studies in the Russian public management practice on the basis of the long-term collaboration programs of Volga State University of Technology and the governmental bodies of the Mari El Republic, Russia.

\section{ACKNOWLEDGMENT}

This researchers was supported by the Ministry of Economic Development and Trade of the Mari El Republic (agreement No. 126/8 of October 8, 2013) and Volga State University of Technology, state-financed scientific-research work No 20 «Efficiency of state control in the sphere of economic activity of the region», No 9 «Development institutions of local markets and the formation of an innovative cluster».

\section{REFERENCES}

Coase, R.H., 1992. The institutional structure of production. Am. Economic Rev., 82: 713-719.

Dritsaki, C. and A. Adamopoulos, 2005. A causal relationship and macroeconomic activity: Empirical results from European Union. Am. J. Applied Sci., 2: 504-507. DOI: 10.3844/ajassp.2005.504.507
Enright, M., 1996. Regional Clusters and Economic Development: A Research Agenda. In: Business Networks: Prospects for Regional Development, Walter, D.G. (Ed.)., Berlin, ISBN-10: 3110151073, pp: 190-213.

Feldman, M.P., 1994. The Geography of Innovation. 1st Edn., Springer Science and Business Media, Dordrecht, ISBN-10: 0792326989, pp: 154.

Kim, Y.D., S. Yoon and H.G. Kim, 2014. An economic perspective and policy implication for social enterprise. Am. J. Applied Sci., 11: 406413. DOI:10.3844/ajassp.2014.406.413

Liu, C.C. and C.Y. Chen, 2004. A computable general equilibrium model of southern region in Taiwan: The impact of the Tainan science-based industrial park. Am. J. Applied Sci., 1: 220-224. DOI:10.3844/ajassp.2004.220.224

North, D., 1994. Economic Performance through Time. Am. Economic Rev., 84: 360-361

Porter, M.E., 2009. Clusters and economic policy: Aligning public policy with the new economics of competition. Institute for Strategy and Competitiveness.

Williamson, O., 2000. The new institutional economics: Taking stock, looking ahead. J. Economic Literature, 38: 595-613. DOI: 10.1257/jel.38.3.595 